\title{
What Do the Mushroom Bodies Do for the Insect Brain? An Introduction
}

\author{
Martin Heisenberg \\ Lehrstuhl für Genetik \\ Biozentrum \\ D-97074 Würzburg, Germany
}

Despite public claims to the contrary, our functional understanding of the brain is still rudimentary. Starting with F.J. Gall's Phrenology of the late eighteenth century, one of the major drives has been to assign functions to discrete regions of the brain. In humans and other primates, lesions and noninvasive imaging techniques have provided fascinating insights into the underlying functional topology of the brain. However, lesions in humans relate brain areas comprising millions of neurons to clinical tests, interrogation, and life histories. Similarly, functional imaging usually ties regions of increased blood flow to mental activity conveyed by verbal or visual instructions. The striking specificity of behavioral and mental deficits after local brain damage is difficult to reconcile with the high degree of integration in the neural circuitry. The situation is as perplexing as that met in brain stimulation experiments in which gross perturbations of sophisticated neural activity patterns in the brain lead, often with long delays, to highly organized behaviors or mental experiences. These approaches, therefore, reveal structure-function relationships that are difficult to interpret in terms of network-based brain models.

After all, assigning behavioral and mental functions to locations in the brain does not explain how the brain works. Brain regions need first to be interpreted as parts of a neural circuitry. One then can hope to obtain cues about the functioning of this system by interfering with a certain part of it and observing how the rest still controls behavior. From this perspective, the interventionist approach is a difficult and largely unexplored task. It is not even obvious (to me) that the brain sciences are ready for it. Given the motivational nature of behavior and the enormous diversity of neuronal interactions, can a basic general model of the brain be established at all at the network level? Is the conceptual and methodological inventory of the behavioral sciences sufficiently sophisticated?

$A$ basic model of how the brain controls be- havior, would, in principle, allow the building of a robot with the same behavioral properties as the respective animal. Such explicit models have been designed for partial aspects of behavior such as color vision in the honeybee (Backhaus 1992), directional hearing in owls (Konishi 1993), or for walking in insects (Graham 1985). However, no such model exists for behavioral control in general. This is where smaller brains can contribute to our understanding of brain function. Animals with small brains, in particular insects, provide the opportunity to analyze the behavioral consequences of interventions (e.g., lesions) in much greater detail and have already, in cases like the ones cited above made it possible to match behavioral functions with the properties of the corresponding neural networks in the brain.

The insect mushroom body (MB) may be a uniquely suitable structure for intervention. Its internal cytoarchitecture seems less complex than that of most other neuropil regions and its bizarre shape suggests a highly specialized function. Being closely associated with the chemosensory system, its role in olfaction can serve as a point of entry for the analysis, and a comparison of the MBs from species with different life styles and ecological constraints may provide useful cues for functional studies.

Moreover, a variety of new approaches for studying the MBs have recently been developed. They take advantage of the rapid advances in areas such as developmental genetics, transgenics, cell and tissue culture, microchemistry, pharmacology, functional imaging, and patch clamping, to name a few. They all recognize the fact that without knowledge of the cellular properties of the tissues involved, their functional involvement cannot be properly assessed. Several of these new approaches are highlighted in this volume.

When Dujardin (1850) first described the MBs in bees and ants, he compared them to the vertebrate cerebral cortex and considered them the seat

LEARN IN G \& MEM ORY 5:1-10 @ 1998 by Cold Spring Harbor Laboratory Press ISSN 1072-0502/98 \$5.00

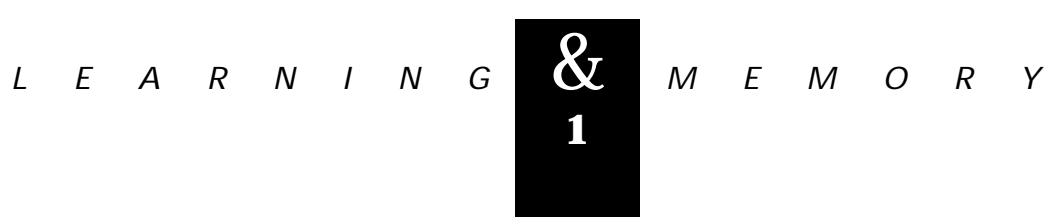


of intelligence. It took nearly 150 years to establish beyond doubt that they are, indeed, involved in something related to intelligence: They are essential for short term memory in odor discrimination tasks. This is a promising start, but it may still be a long way until their function is understood at the circuit level.

I appreciate the editorial decision of Learning $\&$ Memory to devote a special issue of the journal to this topic. The papers that have been contributed provide a good overview of the forefront of this field. They are not narrow ly focused on learning and memory but address a variety of problems broadly related to MB function. Even if the MBs eventually turn out not to be the high-level integration center of the insect brain envisaged by Dujardin, understanding their contribution to a network model of brain function will be of great importance for learning and memory research.

\section{Structure}

Much of what is known about MBs refers to a few insect species. The honeybee, fly (Drosophila), cricket, grasshopper, locust, and cockroach (Periplaneta) dominate the literature, but valuable generalizations and comparative considerations can be drawn from work on other species (for review, see Strausfeld et al. 1998). General reviews on MBs covering a large part of the literature until 1986 have been compiled by Schürmann (1987) and Erber et al. (1987). The honeybee MB has been reviewed by Menzel et al. (1994), whereas that of Drosophila by Heisenberg (1989, 1994) and Davis (1993).

\section{GENERAL STRUCTURE}

The mushroom bodies (corpora pedunculata) of the insect brain are a pair of easily discernible neuropils comprising thousands of densely packed parallel neurons [Kenyon cells, after Kenyon (1896)] running on either side of the central complex from back to front and downward through the protocerebrum. They consist (from back to front) of the rind of Kenyon cell bodies followed by an often cup-shaped protrusion called the calyx, stalk, or peduncle and finally tw o lobes pointing in roughly orthogonal directions (vertical and medial). The MB neuropil is separated from the rest of the brain by a thin sheath of glia lamellae. The Kenyon cells, also called intrinsic neurons, stay within this sheath. Their arborizations constitute its overall shape and they contribute the bulk of the MB neuropil. Kenyon cell bodies send thin fibres to the calyces. These fibers then give rise to the dendrites that make up the calyx neuropil. Each dendritic tree provides an axon into the pedunculus. Kenyon cell dendrites are postsynaptic to afferents reaching the calyces and the axons are interconnected by occasional synapses. At the ventrorostral end of the peduncle the fiber bifurcates, one branch growing upward into the (vertical) $\alpha$ lobe, the other into the (medial) $\beta$-lobe tow ard the mid-plane. Although their location, small cell body size, and arborization pattern makes Kenyon cells easy to recognize as a distinct class of cells, several subtypes can be distinguished by genetic ( $Y$ ang et al. 1995) as well as purely morphological criteria (Musca: Strausfeld 1976; for review, see Schürmann 1987). It will be a task for future research to link these specializations to different functions.

Among the insects, the MBs differ greatly in size and shape. The number of Kenyon cells range from 2500 in Drosophila to 50,000 in Acheta, 170,000 in the honeybee, and 200,000 in Periplaneta (cited in Schürmann 1987). The canonical structure described above has many variations. In bees and crickets (Acheta) for instance, each MB has two prominent calyces whereas in flies (Pow er 1943; Groth 1971; Strausfeld 1976) and dragonflies (Baldues 1924) calyces are poorly developed. Additional stalks and lobes are found in Lepidoptera (Pearson 1971) and Diptera (Groth 1971; Heisenberg 1980). In this special issue, the lobe structure of the Drosophila MBs is explored further using gene expression patterns (Crittenden et al. 1998). In bees and cockroaches, the lobes are organized into parallel layers of histologically distinct tissues (e.g., Mobbs 1982, 1984; Schürmann and Klemm 1984; Rybak and Menzel 1993; Mizunami et al. 1997).

\section{CONNECTIONS}

The MB gets its main input through the calyx. The most salient connection is provided by a group of so-called projection neurons that arborize in single glomeruli of the antennal lobe and terminate in the lateral protocerebrum (bee, lateral protocerebral lobe; fly, lateral horn) as well as in the calyx. Some fibers have been described that enter the calyx from other parts of the brain including the optic lobes, commissural neurons connecting the calyces of the two hemispheres, and a group of feedback neurons from the ipsilateral $\alpha$ - and $\beta$ -

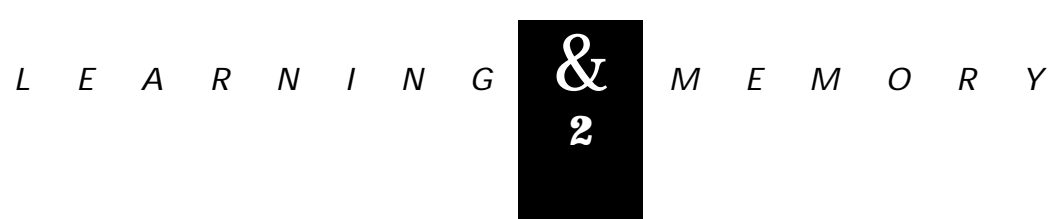




\section{WHAT DO THE MUSHROOM BODIES DO?}

lobes (Gronenberg 1984; for review, see Schürmann 1987). Not much is known about the extrinsic neurons that pick up the MB signals from the Kenyon cells in the peduncle and lobes and transmit them to other parts of the brain. A variety of such cells with individual branching patterns have been documented (Rosentreter and Schürmann 1982; Schildberger 1984; Rybak and Menzel 1993; $\mathrm{Li}$ and Strausfeld 1997). In flies (Strausfeld et al. 1984) and honeybees (see PE1 neuron below) fibers from the $\alpha$-lobe project to the region of the lateral protocerebrum where the projection neurons have their second termination field in the immediate vicinity of large neurons descending to the subesophageal ganglion or thorax. Other target areas of the $\alpha$-lobe in the honeybee are the antennal lobe, the optic tubercle, the ipsilateral calyx (feedback neurons), as well as the contralateral $\alpha$ lobe and protocerebral lobe (Rybak and Menzel 1993). Some fibers connect the $\alpha$ - and $\beta$-lobe (Menzel et al. 1994). The overall number of putative output neurons in the peduncle and lobes is not known as well as that of the input neurons to the calyces. How ever, their number is likely to be at least 1-2 orders of magnitude lower than that of the Kenyon cells, implying a large divergence in the calyx and a corresponding convergence in the peduncle and lobes. A first account of MB output neurons in Drosophila is provided by Ito et al. 1998.

\section{TRANSMITTERS AND NEUROMODULATORS}

As judged by immunohistochemistry in all species studied in this respect, acetylcholine is a major neurotransmitter from projection neurons to Kenyon cells. In bees and crickets, feedback neurons from the lobes to the calyx have been shown to be GABAergic (Bicker et al. 1985). The occurrence of dopamine, noradrenaline, octopamine, and serotonin in the different compartments of the $M B$ varies greatly among insect species and underlines the large variation in the extrinsic MB neurons. The well-known VUMmx1 neuron, an input neuron to the calyces in honeybee, for instance, most likely uses octopamine as its main transmitter (Hammer 1991; see Hammer and Menzel 1998). A variety of transmitter receptor genes have been reported to be expressed in Kenyon cells. In this volume for example, GABA and a GABA receptor subunit are described in cricket MBs by Strambi et al. (1998). The transmitters of the Kenyon cells are not yet known. In bees, some of them display
FMRFamide-like and cholecystokinine (CCK)-like immunoreactivity (cited in Menzel et al. 1994).

\section{STRUCTURAL PLASTICITY}

Larval and adult MBs display a remarkable structural plasticity. In some coleopteran and orthopteroid species, and most dramatically in the rove beetle Aleochara (Bieber and Fuldner 1979), MB neuroblasts persist deep into adulthood, generating new Kenyon cells (Cayre et al. 1996). In flies and bees that show little or no neurogenesis during adulthood, Kenyon cells shed their fibers and regrow them during metamorphosis (Technau and Heisenberg 1982; P.G. Mobbs, unpubl.). This reorganization is investigated by new techniques in a contribution of Armstrong et al. (1998). In Drosophila, even in the adult, Kenyon cells can shed their fibers or grow new ones (Balling et al. 1987). At least some of the structural modifications depend on experience. Larval crowding leads to more Kenyon cell fibers at eclosion than larval growth at a low population density (Heisenberg et al. 1995). Olfactory (or social) deprivation during adulthood reduces the fiber number in the peduncle (Technau 1984) whereas visual deprivation has no comparable effect but, instead, reduces the volume of the calyx (Barth and Heisenberg 1997). In the latter case, experience can be distinguished from activity as even unilateral blindfolding reduces the volume of the ipsilateral calyx. In bees and ants, the transition from the nursing to the worker cast is associated with volume changes in the calyx (Withers et al. 1993, 1995; Durst et al. 1995; Gronenberg et al. 1996). A paper by Fahrbach et al. (1998) demonstrates a volume increase of the MB neuropil during the first week of adult bees that are spatially, visually, and socially deprived.

\section{Function}

\section{FUNCTIONAL ANATOMY}

The Kenyon cells are only two synapses aw ay from the olfactory receptors on the antenna. The simple, anatomy-based assumption that the glomeruli of the antennal lobe receive receptor fibers of the same chemospecificity and that the projection neurons relay this information from each glomerulus to the calyx is certainly a simplification but it may still embody some important properties of the olfactory input to the MB. As the anatomy suggests, a limited number of projection neurons with distinct chemospecificities carry the informa-

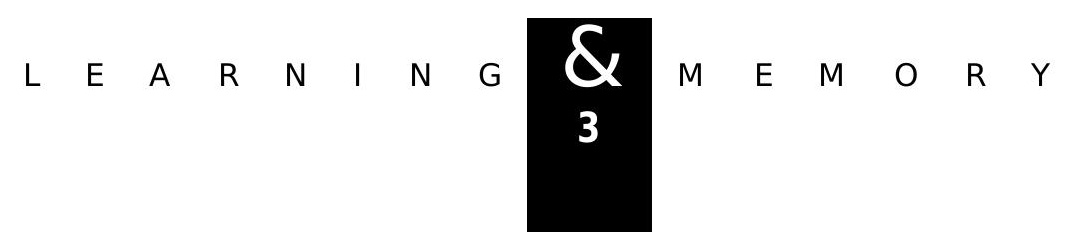


tion that enables the animal to discriminate thousands of odors. This can only be achieved by evaluating the activity of the projection neurons in a combinatorial manner. The divergence from the projection neurons to the Kenyon cells mentioned above may reflect such a combinatorial principle (Heisenberg 1989; for review, see also Laurent et al. 1998).

A characteristic feature of MBs is the large number of very thin and long parallel fibers of the Kenyon cells. Length appears to be important, as in the small Drosophila brain, peduncle and lobes make the best possible use of the available space whereas in larger brains (e.g., cricket, bee, cockroach) Kenyon cell fibers do not extend all the way to the margin of the midbrain neuropil. Schürmann (1987) and Erber et al. (1987) suggested that MBs with their bundles of long, thin fibers might be involved in the temporal integration of sensory signals. A further puzzling question is the orthogonal orientation of the stalk and lobes. Might they represent Cartesian coordinates (Bullock and Horridge 1965) or do the lobes just need to reach certain target areas? Without an interpretation of these anatomical features, our functional understanding of the MBs will remain incomplete.

\section{COMPARATIVE STUDIES}

Throughout the history of MB research, comparative observations have fueled speculations about MB function. For instance, it had already been noted early in the century that MBs are particularly large in the eusocial insects and that honeybee drones have smaller MBs (but larger eyes and optic lobes) than worker bees (Jonescu 1909). As mentioned briefly above, in Hymenoptera, the MB calyces are highly differentiated whereas among the Isoptera, Diptera, and some Lepidoptera, complex lobe systems have evolved (How se 1974). It will be interesting to find out whether the functional correlates of these structural differences are variations of a common theme or whether evolution has opportunistically used this structure for entirely different purposes. The provocative review by Strausfeld et al. (1998) offers a systematic comparison of MBs in Insecta and other arthropods.

\section{SURGICAL LESIONS: LOCAL COOLING}

AND ELECTRICAL STIMULATION

Mechanical lesions in the MBs are difficult to interpret because inevitably, neurons outside the
MBs are also affected. Ablation of the calyx impairs extrinsic neurons, which deliver sensory input to other brain regions as well, and the peduncle and lobes are difficult to reach without destroying other neuropils. A variety of behavioral effects have been reported after lesioning the MBs (for summary, see Erber et al. 1987). Among these are atypical reflexes, impairment of flight, rivaling motor patterns, and a transient increase in locomotor activity. Already in 1960, Drescher reported increased odor thresholds after calyx ablation in Periplaneta (Drescher 1960). Vowles (1964) found a loss of olfactory memory in ants after cuts in and around the MBs and 10 years later, Menzel et al. (1974) observed an impairment of olfactory short term memory in honeybees after puncturing the calyx or $\alpha$-lobe. They could even interfere with this memory by locally cooling parts of the MBs in a short time window after training (Menzel et al. 1974; Erber et al. 1980).

Electrical stimulation experiments suffer from similar difficulties of interpretation as ablation studies. Neither is it possible to determine with certainty which neurons in the vicinity of the electrode tip are stimulated, nor can one tell how the various cells will respond to the stimulation. Accordingly, a variety of behavioral effects have been obtained from stimulating the MBs. These range from activation or inhibition of locomotion to triggering specific motor patterns such as different songs in crickets and grasshoppers (Huber 1965; Wadepuhl 1983; for review, see Erber et al. 1987).

\section{GENETIC AND DEVELOPMENTAL IMPAIRMENT OF MB FUNCTION}

In the early 1980s, single gene variants with defective MBs were discovered in Drosophila. The behavior of two such lines, mutated in different genes and showing different etiologies of the MB defects, were studied in behavior. Flies with $>90 \%$ of the Kenyon cells missing were remarkably normal in many behaviors, including their naive responses to attractive and repulsive scents, but they displayed a striking amnesia in odor conditioning (Heisenberg et al. 1985). More recently, de Belle and Heisenberg (1994) treated first instar larvae with the cytostatic drug hydroxyurea (HU) to ablate the four MB neuroblasts in each brain hemisphere that generate all the postembryonic Kenyon cells (Prokop and Technau 1994) and a fifth neuroblast contributing neurons to the antennal lobe. Again, these flies perceive, but do not

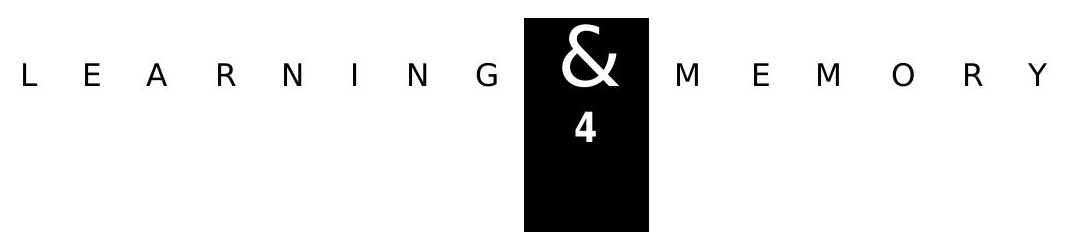




\section{WHAT DO THE MUSHROOM BODIES DO?}

remember, odors, while being surprisingly normal otherwise. Finally, Connolly et al. (1996) used enhancer detector strains of Drosophila (Brand and Perrimon 1993) to express in the Kenyon cells a transgene for a constitutively activated G-protein $\alpha$-subunit. This presumably blocked the intracellular signal from the reinforcer (electric shock). In agreement with the mutant and chemical ablation results, these flies could not remember to avoid the odors, which had earlier been combined with electric shock. It now appears that some of these new ablation techniques can also be applied to other insects. Malun (1998) has ablated the MBs in the honeybee by applying $\mathrm{HU}$ to early larvae.

\section{ELECTRICAL RECORDING}

Single neuron recordings and field potentials of MBs have been obtained in large insects such as honeybee, locust, cricket, and cockroach. They confirm that MBs receive multimodal sensory input and that its processing goes on from seconds to sometimes minutes after stimulation (e.g., Schildberger 1984; Homberg 1984; Gronenberg 1986; Li and Strausfeld 1997). A few cells, again mostly in the honeybee, have been characterized in detail. In the projection neurons connecting the antennal lobe to the calyx, a whole spectrum of different chemical and temporal response characteristics are observed (Schildberger 1984; Homberg 1984; Kanzaki et al. 1989; Boeckh et al. 1990). Recently, G. Laurent and coworkers discovered in locusts and bees a stimulus-induced oscillatory synchronization of the projection neurons which can be observed in the local field potential of the calyx (Wehr and Laurent 1996). The synchronization is generated by a fast GABAergic inhibition from local interneurons in the antennal lobe (MacLeod and Laurent 1996). Its significance for odor processing in the Kenyon cells and for the representation of odor quality in behavior (Stopfer et al. 1997) is currently under investigation (see Laurent et al. 1998).

Two prominent identified extrinsic neurons of the honeybee implicate the MB in olfactory conditioning (Hammer and Menzel 1995). One of these neurons is the above-mentioned VUMmx 1 neuron that originates in the subesophageal ganglion and abundantly invades the antennal lobe, calyces, and lateral protocerebral lobe in both brain hemispheres. It can be driven to represent the unconditioned stimulus (US) in olfactory conditioning of the proboscis extension reflex (PER) as its depolarization can be shown to substitute for the sugar reward (Hammer 1993). As mentioned above, it contains octopamine (Kreissl et al. 1991) and, most likely, uses it as its transmitter. Interestingly, local injection of octopamine into the calyx and antennal lobe can substitute for the activity of the VUMmx1 neuron in PER conditioning as show $n$ by Hammer and Menzel (1998; see also Hammer et al. 1993).

The second neuron, PE1, operates downstream of the Kenyon cells, connecting the $\alpha$-lobe and peduncle to the lateral protocerebral lobe, the same general target area where projection neurons, VUMmx 1, and descending neurons meet. Rybak and Menzel (1998) show that PE1 receives input from a large number of Kenyon cells of the three major MB subdivisions (collar, lip, and basal ring). In the lateral protocerebrum, PE1 may contact the same descending neurons as the projection neurons that provide the input to the Kenyon cells. Therefore, this loop via the MBs can be regarded as a parallel olfactory pathway as has been first pointed out for flies by Strausfeld et al. (1984; see also Rybak and Menzel 1993; Hammer and Menzel 1995; Hammer 1997). PE1 displays associative plasticity in its response properties. After the first olfactory conditioning trial in which a certain odor $\left(\mathrm{CS}^{+}\right)$has been rew arded, PE1 reduces its response specifically to this odor and not to the unpaired one $\left(\mathrm{CS}^{-}\right)$. With further conditioning trials, its response to the $\mathrm{CS}^{+}$differentially increases (Mauelshagen 1993). The associative effects are observed only for a few minutes after the training, implying that PE1 is not located downstream of a site of lasting memory storage.

\section{BIOCHEMISTRY}

In Drosophila, mutants and transgenic flies have established a link between olfactory memory and intracellular CAMP signaling (for review, see deZazzo and Tully 1995; Davis 1996). Interestingly, several genes of this signaling pathway are preferentially expressed in Kenyon cells. The dunce CAMP phosphodiesterase (Nighorn et al. 1991) and CAMP-dependent protein kinase (PKA; Drain et al. 1991; Skoulakis et al. 1993) are concentrated in all compartments of the MB whereas the $\mathrm{Ca} /$ calmodulin-dependent adenylate cyclase $(A C)$ of the rutabaga gene is found at elevated concentrations only in the peduncle and lobes (Han et al. 1992). Recently, a dopamine receptor gene (damb) that is expressed in Kenyon cells has been discovered. Like $A C$, the receptor is preferentially localized in the peduncle and lobes where dopaminergic ex-

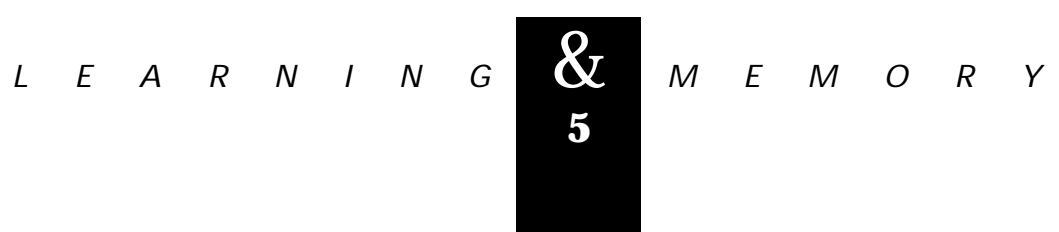


trinsic neurons terminate (Han et al. 1996). Its involvement in olfactory memory has yet to be demonstrated. High concentrations of PKA have also been found in the honeybee MB (Altfelder and Müller 1991). However, while one-trial olfactory conditioning as well as local octopamine injections lead to an elevated level of PKA activity in the antennal lobe (Hildebrandt and Müller 1995a,b), no such effects have so far been observed for the calyx $(H$. Hildebrandt and $U$. Müller, pers. comm.).

\section{Concluding Remarks}

The MBs of Drosophila and the honeybee are involved in certain forms of olfactory conditioning. How they contribute to the behavioral plasticity is less well understood. In flies, CAMP signaling is required in the Kenyon cells, suggesting that synaptic transmission between Kenyon cells and extrinsic output neurons is modified by the respective reinforcer. Whether the synaptic plasticity in the Kenyon cells is sufficient to provide olfactory memory remains an open question.

In the bee, the properties of the PEI neuron are consistent with the idea that the MBs mediate short term memory in odor discrimination tasks. Again, how the MBs and PE1 are involved is not yet understood (see Rybak and Menzel 1998). The reinforcer in PER conditioning is delivered by the VUMmx 1 neuron to three locations along the olfactory pathway. It is tempting to assume that octopamine triggers the CAMP cascade and that CAMP-dependent synaptic plasticity occurs at each of these sites. At which of them synaptic plasticity is essential for odor memory to occur, and whether synaptic plasticity at other brain sites is required in addition remains to be determined (see Hammer and Menzel 1998).

Among the many similarities in the results from MB studies in flies and bees a few fascinating differences emerge. Although it is too early to tell whether they reflect only differences of our state of knowledge (see below), or whether the two learning paradigms (PER conditioning in the bee vs. electroshock conditioning of freely walking Drosophila) or actual species differences are responsible, they are worth mentioning again. In the calyx-type MB of the honeybee, octopamine appears to be the relevant modulatory transmitter driving CAMP-dependent olfactory learning. This transmitter is delivered by the VUMmx 1 neuron to the calyces but not to the peduncle and lobes. In the lobe-type MB of Drosophila, olfactory learning along with the CAMP cascade seem to be driven by dopamine or serotonin (Tempel et al. 1984), and dopamine receptor as well as the rutabaga adenylyl cyclase $(A C)$ are found preferentially in the peduncle and lobes but not the calyx (Han et al. 1992, 1996). If these are, indeed, differences betw een the two MB systems, they should have interesting consequences in olfactory behavior. A new study in Drosophila now demonstrates an AC coupled octopamine receptor preferentially expressed in all parts of the MBs including the calyces (Han et al. 1998).

Olfactory associative memory is not the only behavioral function for which the MBs are required. For instance, a paper by Martin et al. (1998) shows that a block in the MB pathway leads to elevated locomotor activity as had been observed by Huber $(1960,1965)$ for crickets and grasshoppers. The MB-less flies have a difficulty to stop walking once started. Possibly this impairment is related to their difficulty to stop courting young males as observed by Neckameyer (1998). The MBs process multimodal input but, as one article by Wolf et al. (1998) shows in flies they are dispensable for visual, tactile/ideothetic spatial, or motor learning. How ever, neither long term memory nor higher cognitive functions have been tested with these forms of learning. Indeed, in the cockroach, Mizunami et al. (1993) have observed a defect in a more demanding spatial memory task after surgical lesions in the MBs, and for MB-less flies, our preliminary data suggest that a slight modification of the visual learning paradigm does reveal a behavioral deficit (L. Liu, R. Wolf, and M. Heisenberg, in prep.).

Evidently, the question that motivated the early pioneers in the field, "What is the role of the MBs in behavior?" is still the central issue and is largely unanswered. Today we should rephrase it, however, and ask: "What is the function of the MBs in a circuit model of the brain?" It should be remembered that the involvement of MBs in olfactory memory and locomotion control so far does not provide a plausible explanation for the bizarre, highly conserved structure of the MBs. Understanding the MBs in the context of a netw ork model not only requires scrutinizing the behavioral pathology of MB-less animals (using several independent methods of intervention), one also needs to know in more detail the $M B$ circuitry and its intrinsic molecular differentiation. The papers in this special volume address and advance many of the is-

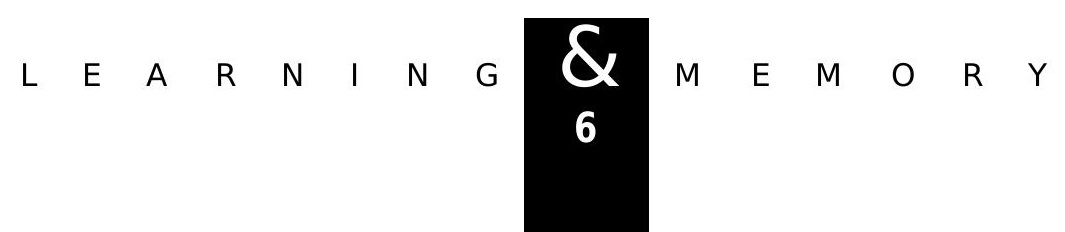


sues that have to be taken into account if one wants to find out what the MBs do for the insect brain.

\section{Acknowledgments}

I am grateful to T. Zars, R.L. Davis, R. Menzel, and N.J. Strausfeld for their critical comments on the manuscript and to $H$. Spanheimer for writing parts of it.

The publication costs of this article were defrayed in part by payment of page charges. This article must therefore be hereby marked "advertisement" in accordance with 18 USC section 1734 solely to indicate this fact.

\section{References}

Altfelder, K. and U. Müller. 1991. Cyclic

nucleotide-dependent protein kinases in the neural tissue of the honeybee, Apis mellifera. Insect Biochem. 21: 487-494.

Armstrong, J.D., J.S. de Belle, Z. Wang, and K. Kaiser. 1998. Metamorphosis of the mushroom bodies; large-scale rearrangements of the neural substrates for associative learning and memory in Drosophila. Learn. \& Mem. (this issue).

Backhaus, W. 1992. Color vision in honeybees. Neurosci. Biobehav. Rev. 16: 1-12.

Baldus, K. 1924. Untersuchungen über Bau und Funktion des Gehirns der Larve und Imago von Libellen. Z. Wiss. Zool. 121: 557-620.

Balling, A., G.M. Technau, and M. Heisenberg. 1987. Are the structural changes in adult Drosophila mushroom bodies memory traces? Studies on biochemical learning mutants. J. Neurogenet. 4: 65-73.

Barth, M. and M. Heisenberg. 1997. Vision affects mushroom bodies and central complex in Drosophila melanogaster. Learn. \& Mem. 4: 219-229.

Bicker, G., S. Schäfer, and T.G. Kingan. 1985. Mushroom body feedback interneurons in the honey bee show GABA-like immunoreactivity. Brain Res. 360: 394-397.

Bieber, M. and D. Fuldner. 1979. Brain growth during the adult stage of a holometabolous insect. Naturwissenschaften 66: 426.

Boeckh, J., P. Distler, K.D. Ernst, M. Hösl, and D. Malun. 1990. Olfactory bulb and antennal lobe. In Chemosensory information processing (ed. Schild), pp. 201-207. Springer-Verlag, Berlin, Germany.

Brand, A.H. and N. Perrimon. 1993. Targeted gene expression as a means of altering cell fate and generating dominant phenotypes. Development 118: 401-415.

Bullock, T.H. and G.A. Horridge. 1965. Structure and function in the nervous system of invertebrates. vol. 2. Freeman, San Francisco, CA.
Cayre, M., C. Strambi, P. Charpin, R. Augier, M.R. M eyer, J.S. Edwards, and A. Strambi. 1996. Neurogenesis in adult insect mushroom bodies. J. Comp. Neurol. 371: 300-310.

Connolly, J.B., I.J.H. Roberts, J.D. Armstrong, K. Kaiser, M. Forte, T. Tully, and C.J. O'Kane. 1996. Associative learning disrupted by impaired $\mathrm{G}(\mathrm{S})$ signaling in Drosophila mushroom bodies. Science 274: 2104-2107.

Crittenden, J.R., E.M.C. Skoulakis, K.-A. Han, D. Kalderon, and R.L. Davis. 1998. Tripartite mushroom body architecture revealed by antigenic markers. Learn. \& Mem. (this issue).

Davis, R.L. 1993. Mushroom bodies and Drosophila learning. Neuron 11: 1-14.

- - . 1996. Physiology and biochemistry of Drosophila learning mutants. Physiol. Rev. 76: 299-317.

de Belle, J.S. and M. Heisenberg. 1994. Associative odor learning in Drosophila abolished by chemical ablation of mushroom bodies. Science 263: 692-695.

deZazzo, J. and T. Tully. 1995. Dissection of memory formation: From behavioral pharmacology to molecular genetics. Trends Neurosci. 18: 212-218.

Drain, P., E. Folkers, and W.G. Quinn. 1991.

CAM P-dependent protein kinase and the disruption of learning in transgenic flies. Neuron 6: 71-82.

Drescher, W. 1960. Regenerationsversuche am Gehirn von Periplaneta americana unter Berücksichtigung von Verhaltensänderung und Neurosekretion. Z. Morphol. Ö kol. Tiere 48: 576-649.

Dujardin, F. 1850. Memoire sur le systeme nerveux des insects. Ann. Sci. Nat. Zool. 14: 195-206.

Durst, C., S. Eichmüller, and R. M enzel.1994. Development and experience lead to increased volume of subcompartments of the honey bee mushroom body. Behav. Neural Biol. 62: 259-263.

Erber, J., U. Homberg, and W. Gronenberg. 1987. Functional roles of the mushroom bodies in insects. In Arthropod brain: Its evolution, development, structure, and functions (ed. P. Gupta), pp. 485-511. John Wiley \& Sons, New York, NY.

Erber, J., T. Masuhr, and R. Menzel. 1980. Localization of short-term memory in the brain of the bee Apis mellifera. Physiol. Entomol. 5: 343-358.

Fahrbach, S.E., D. Moore, E.A. Capaldi, S.M. Farris, and G.E. Robinson. 1998. Experience-expectant plasticity in the mushroom bodies of the honeybee. Learn. \& Mem. (this issue).

Graham, D. 1985. Pattern and control of walking insects. Adv. Insect Physiol. 18: 131-140.

Gronenberg, W. 1984. Das Protocerebrum der Honigbiene im Bereich des Pilzkörpers-eine

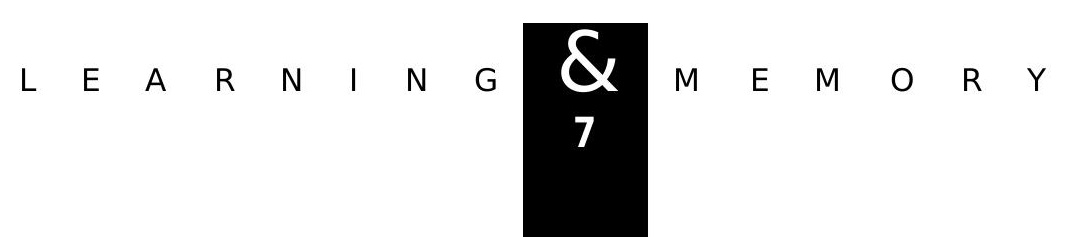




\section{Heisenberg}

neurophysiologisch-anatomische Charakterisierung. Ph.D. dissertation, Freie U niversität, Berlin, Germany.

- - . 1986. Physiological and anatomical properties of optical input-fibres to the mushroom body in the bee brain. J. Insect. Physiol. 32: 695-704.

Gronenberg, W., S. Heeren, and B. Hölldobler. 1996. Age-dependent and task-related morphological changes in the brain and the mushroom bodies of the ant, Camponotus floridanus. J. Exp. Biol. 119: 2011-2019.

Groth, U. 1971. Vergleichende U ntersuchungen Ÿber die Topographie und Histologie des Gehirns der Dipteren. Zool. Jahrb. Abt. Anat. 88: 203-319.

Hammer, M. 1993. An identified neuron mediates the unconditioned stimulus in associative learning in honeybees. Nature 366: 59-63.

--1 . 1997. The neural basis of associative reward learning in honeybees. Trends Neurosci. 20: 245-252.

Hammer, M. and R. Menzel. 1995. Learning and memory in honeybees. J. Neurosci. 15: 1617-1630.

- - . 1998. Multiple sites of associative odor learning as revealed by local brain microinjections of octapamine in honeybees. Learn. \& Mem. (this issue).

Hammer, M., R. Menzel, and U. Schneider. 1993. An identified neuron mediates the unconditioned stimulus in associative learning in honeybees. Nature 366: 59-63.

Han, K.-A., N.S. Millar, M.S. Grotewiel, and R.L. Davis. 1996. DAMB, a novel dopamine receptor expressed specifically in Drosophila mushroom bodies. Neuron 16: 1-20.

Han, K.-A., N.S. Millar, and R.L. Davis. 1998. A novel octopamine receptor with preferential expression in Drosophila mushroom bodies. J. Neurosci. (in press).

Han, P.L., L.R. Levin, R.R. Reed, and R.L. Davis. 1992. Preferential expression of the Drosophila rutabaga gene in mushroom bodies, neural centers for learning in insects. Neuron 9: 619-627.

Heisenberg, M. 1980. Mutants of brain structure and function: What is the significance of the mushroom bodies in behavior. In Development and neurobiology of D rosophila (ed. O. Siddiqui, P. Babu, L.M. Hall, and I.C. Hall). Plenum Press, New York, NY.

- - . 1989. Genetic approach to learning and memory (mnemogenetics) in Drosophila melanogaster. In Fortschritte der Zoologie. Fundamentals of memory formation: Neuronal plasticity and brain function (ed. M. Lindauer), pp. 3-45. G. Fischer, Stuttgart, Germany.

--1 . 1994. Central brain function in insects: Genetic studies on the mushroom bodies and central complex in Drosophila. In Fortschritte der Zoologie. Neural basis of behavioral adaptions (ed. W. Rathmayer), pp. 61-79. G. Fischer, Stuttgart, Germany.

Heisenberg, M., A. Borst, S. Wagner, and D. Byers. 1985. Drosophila mushroom body mutants are deficient in olfactory learning. J. Neurogenet. 2: 1-30.

Heisenberg, M., M. Heusipp, and T. Wanke. 1995. Structural plasticity in the Drosophila brain. J. Neurosci.

15: 1951-1960.

Hildebrandt, H. and U. M üller. 1995a. O ctopamine mediates rapid stimulation of protein kinase $A$ in the antennal lobe of honeybees. J. Neurobiol. 27: 44-50.

--1 . 1995b. PKA activity in the antennal lobe of honeybees is regulated by chemosensory stimulation in vivo. Brain Res. 679: 281-288.

Homberg, U. 1984. Processing of antennal information in extrinsic mushroom body neurons of the bee brain. J. Comp. Physiol. 154: 825-836.

Howse, P.E. 1974. Design and function in the insect brain. In Experimental analysis of insect behaviour (ed. L.

Barton-Brown), pp. 180-194. Springer, Berlin, Germany.

Huber, F. 1960. Untersuchungen über die Funktion des Zentralnervensystems und insbesondere des Gehirns bei der Fortbewegung und der Lauterzeugung der Grille. Z. Vergl. Physiol. 44: 60-132.

- - - 1965. Neural integration (central nervous system). In The physiology of Insecta (ed. M. Rockstein), vol. 2, pp. 333-406. Academic Press, New York, NY.

Ito, K., K. Suzuki, P. Estes, M. Ramaswami, D. Yamamoto, and N.J. Strausfeld. 1998. The organization of extrinsic neurons and their implications regarding the functional roles of the mushroom bodies in Drosophila melanogaster M eigen. Learn. \& Mem. (this issue).

Jonescu, C.N. 1909. Vergleichende U ntersuchungen über das Gehirn der Honigbiene. Z. Naturwiss. 45: 111-180.

Kanzaki, R., E.A. Arbas, N.J. Strausfeld, and J.G. Hildebrand. 1989. Physiology and morphology of projection neurons in the antennal lobe of the male moth Manduca sexta. J. Comp. Physiol. 165: 427-453.

Kenyon, F.C. 1896. The brain of the bee-A preliminary contribution to the morphology of the nervous system of the Arthropoda. J. Comp. Neurol. 6: 134-210.

Konishi, M. 1993. Listening with two ears. Sci. Am. 268: 66-73.

Kreissl, S., S. Eichmüller, G. Bicker, J. Rapus, and M. Eckert. 1991. The distribution of octopamine-like immunoreactivity in the brain of the honeybee. In Synapse-transmission-modulation (ed. N. Elsner and $H$. Penzlin), p. 407. Georg Thieme Verlag, Stuttgart, Germany. 


\section{WHAT DO THE MUSHROOM BODIES DO?}

Laurent, G., K. MacLeod, M. Stopfer, and M. Wehr. 1998. Spatiotemporal structure of olfactory inputs to the mushroom bodies. Learn. \& Mem. (this issue).

Li. Y,-S. and N.J. Strausfeld. 1997. Morphology and sensory modality of mushroom body efferent neurons in the brain of the cockroach, Periplaneta americana. J. Comp. Neurol. 387: 631-650.

MacLeod, K. and G. Laurent. 1996. Distinct mechanisms for synchronization and temporal pattering of odor-encoding neural assemblies. Science 274: 976-979.

Malun, D. 1998. Early development of mushroom bodies in the brain of the honeybee Apis mellifera as revealed by BrdU incorporation and ablation experiments. Learn. \& Mem. (this issue).

Martin, J.-R., R. Ernst, and M. Heisenberg. 1998. Mushroom bodies suppress locomotor activity in Drosophila melanogaster. Learn. \& Mem. (this issue).

Mauelshagen, J. 1993. Neural correlates of olfactory learning in an identified neuron in the honeybee brain. J.

Neurophysiol. 69: 609-625.

Menzel, R., J. Erber, and T. M asuhr. 1974. Learning and memory in the honeybee. In Experimental analysis of insect behaviour (ed. L. Barton-Brown), pp. 195-217. Springer, Berlin, Germany.

Menzel, R., C. Durst, J. Erber, S. Eichmüller, M. Hammer, H. Hildebrandt, J. M auelshagen, U. M üller, H. Rosenboom, J. Rybak, S. Schäfer, and A. Scheidler. 1994. The mushroom bodies in the honeybee: From molecules to behaviour. In Fortschritte der Zoologie. Neural basis of behavioral adaptions (ed. W. Rathmayer), pp. 81-102. G. Fischer, Stuttgart, Germany.

Mizunami, M., J.M. W eibrecht, and N.J. Srausfeld. 1993. A new role for the insect mushroom bodies: Place memory and motor control. In Biological neural networks in invertebrate neuroethology and robotics (ed. R.D. Beer, R.E. Ritzman, and T. McKenna), pp. 199-225. Academic Press, New York, NY.

Mizunami, M., M. Iwasaki, M. Nishikawa, and R. O kada. 1997. Modular structures in the mushroom body of the cockroach. Neurosci. Lett. 229:153-156.

Mobbs, P.G. 1982. The brain of the honey bee Apis mellifera. The connections and spatial organization of the mushroom bodies. Philos. Trans. R. Soc. Lond. B Biol. Sci. 298: 309-354.

- - - 1984. Neural networks in the mushroom bodies of the honeybee. J. Insect Physiol. 30: 43-58.

Neckameyer, W. 1998. Dopamine and mushroom bodies in Drosophila: Experience-dependent and -independent aspects of sexual behavior. Learn. \& Mem. (this isssue).

Nighorn, A., M.J. Healy, and R.L. Davis. 1991. The cyclic AMP phosphodiesterase encoded by the Drosophila dunce gene is concentrated in the mushroom body neuropil. Neuron 6: 455-467.

Pearson, L. 1971. The corpora pedunculata of Sphinx ligustri I. and other Lepidopteralepidoptera: An anatomical study. Phil. Trans. R. Soc. Lond. B 259: 477-516.

Power, M. 1943. The brain Drosophila melanogaster. J. Morphol. 72: 517-559.

Prokop, A. and G.M. Technau. 1994. Normal function of the mushroom body defect gene of Drosophila is required for the regulation of the number and proliferation of neuroblasts. Dev. Biol. 161: 321-337.

Rybak, J. and R. Menzel. 1993. Anatomy of the mushroom bodies in the honeybee brain: The neuronal connections of the alpha-lobe. J. Comp. Neurol. 334: 444-465.

--- . 1998. Integrative properties of the Pel-neuron, a unique mushroom body output neuon. Learn. \& Mem. (this issue).

Schildberger, K. 1984. Multimodal interneurons in the cricket brain: Properties of identified extrinsic mushroom body cells. J. Comp. Physiol. 154: 71-79.

Schürmann, F.W. and N. Klemm. 1984.

Serotonin-immunoreactive neurons in the brain of the honeybee. J. Comp. Neurol. 225: 570-580.

Schürmann, F.W. 1987. The architecture of the mushroom bodies and eelated neuropils in the insect brain. In Arthropod brain: Its evolution, development, structure, and functions (ed. A.G. Gupta), pp. 231-275. John Wiley \& Sons, New York, NY.

Skoulakis, E.M., D. Kalderon, and R.L. Davis. 1993. Preferential expression in mushroom bodies of the catalytic subunit of protein kinase $A$ and its role in learning and memory. Neuron 11: 197-208.

Stopfer, M., S. Bhagavan, B.H. Smith, and G. Laurent. 1997. Impaired odour discrimination on desynchronization of odour-encoding neural assemblies. Nature 390: 70-74.

Strambi, C., M. Cayre, D.B. Sattelle, R. Augier, P. Charpin, and A. Strambi. 1998. Immunocytochemical mapping of an RDL-like GABA receptor subunit and of GABA in brain structures related to learning and memory in the cricket Acheta domesticus. Learn. \& Mem. (this issue).

Strausfeld, N.J. 1976. Atlas of an insect brain. Springer, Berlin, Germany.

Strausfeld, N.J., U. Bassemir, N. Singh, and J.P. Bacon. 1984. O rganizational principles of outputs from dipteran brains. J. Insect Physiol. 30: 73-93.

Strausfeld, N.J., L. Hansen, Y. Li, R.S. Gomez, and K. Ito. 1998. Evolution, discovery, and interpretations of arthropod mushroom bodies. Learn. \& Mem. (this issue). 


\section{Heisenberg}

Technau, G. 1984. Fiber number in the mushroom bodies of adult Drosophila melanogaster depends on age, sex and experience. J. Neurogenet. 1: 113-126.

Technau, G. and M. Heisenberg. 1982. Neural reorganization during metamorphosis of the corpora pedunculata in Drosophila melanogaster. Nature 295: 405-407.

Tempel, B.L., M.S. Livingstone, and W.G. Q uinn. 1984. Mutations in the dopa decarboxylase gene affect learning in Drosophila. Proc. Natl. Acad. Sci. 81: 3577-3581.

Vowles, D.M. 1964. Models in the insect brain. In Neural theory and modeling (ed. E. Reriss). Stanford U niversity Press, Stanford, CA.

Wadepuhl, M. 1983. Control of grasshopper singing behaviour by the brain: Responses to electrical stimulation. Z. Tierpsychol. 63: 173-200.

Wehr, M. and G. Laurent. 1996. O dour encoding by temporal sequences of firing in oscillatingoscillatin neural assemblies. Nature 384: 161-166.

Withers, G.S., S.E. Fahrbach, and G.E. Robinson. 1993. Selective neuroanatomical plasticity and division of labour in the honeybee. Nature 364: 238-240.

--- . Effects of experience and juvenile hormone on the organization of mushroom bodies of honey bees. J. Neurobiol. 26: 130-144.

Wolf, R.W., T. Wittig, L. Liu, G. W ustmann, D. Eyding, and M. Heisenberg. 1998. Drosophila mushroom bodies are dispensable for visual, tactile, and motor learning. Learn. \& Mem. (this issue).

Yang, M.Y., J.D. Armstrong, I. Vilinsky, N.J. Strausfeld, and K. Kaiser. 1995. Subdivision of the Drosophila mushroom bodies by enhancer-trap expression patterns. Neuron 15: 45-54.

Received January 26, 1998; accepted in revised form April 17, 1998. 


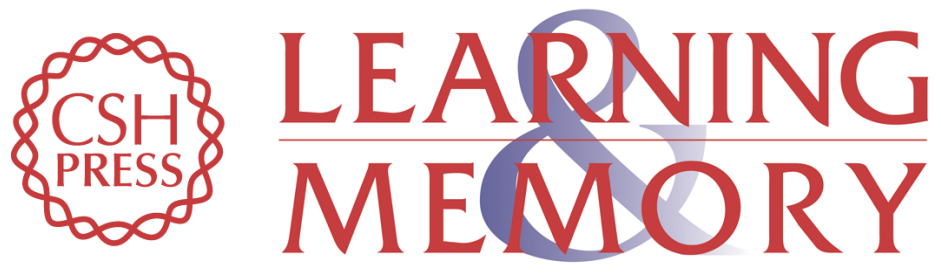

\section{What Do the Mushroom Bodies Do for the Insect Brain? An Introduction}

Martin Heisenberg

Learn. Mem. 1998, 5:

Access the most recent version at doi:10.1101/lm.5.1.1

References This article cites 57 articles, 8 of which can be accessed free at: http://learnmem.cshlp.org/content/5/1/1.full.html\#ref-list-1

License

Email Alerting Receive free email alerts when new articles cite this article - sign up in the box at the Service top right corner of the article or click here. 